\title{
ANALISIS KOORDINASI OVER CURRENT RELAY DAN GROUND FAULT RELAY TERHADAP KEANDALAN SISTEM
}

\author{
I Nengah Sunaya ${ }^{1}$ dan I Gede Suputra Widharma ${ }^{2}$ \\ ${ }^{1}$ Program Studi Teknik Listrik, Jurusan Teknik Elektro, Politeknik Negeri Bali \\ Kampus Bukit Jimbaran, Kuta Badung, Bali \\ Email: nsunaya@pnb.ac.id \\ ${ }^{2}$ Program Studi Teknik Otomasi, Jurusan Teknik Elektro, Politeknik Negeri Bali \\ Kampus Bukit Jimbaran, Kuta Badung, Bali \\ Email: suputra.widharma@gmail.com
}

\begin{abstract}
Abstrak - Penelitian ini dilaksanakan berdasarkan studi kasus di feeder Gardu Induk 20 kV Jababeka. Data existing menunjukkan kondisi yang sesuai dengan perbedaan yang tidak terlalu jauh, secara keseluruhan setting pada Overcurrent Relay (OCR) - Ground Fault Relay (GFR) yang ada di lapangan dalam kondisi baik. Dari hasil perhitungan dapat dilihat bahwa besarnya arus gangguan hubung singkat dipengaruhi oleh jarak titik gangguan. Penggunaan relay arus lebih atau over current relay mempunyai peran yang sangat penting dalam memproteksi system tenaga listrik. Penyetelan waktu minimum dari relay arus lebih di penyulang tidak lebih kecil dari 0.3 detik. Pertimbangan ini diambil agar relay tidak sampai trip lagi in rush current dari transformator distribusi yang memang sudah tersambung di jaringan distribusi sewaktu PMT penyulang tersebut dioperasikan. Waktu kerja relai pada penyulang lebih cepat jika dibandingkan dengan waktu kerja pada sisi incoming dengan selisih waktu rata-rata sebesar 0.4 detik untuk sisi gangguan satu fasa. Namun untuk sisi gangguan tiga fasa dan dua fasa, waktu kerja relai memiliki selisih waktu 0,4 detik dan berangsur meningkat dengan rata-rata kenaikan 0,1 detik ketika panjang kabel semakin jauh (ditinjau pada jarak $0 \%, 25 \%$, $50 \%, 75 \%$ dan $100 \%)$.
\end{abstract}

Kata kunci: Koordinasi, Relay, OCR, GFR, Keandalan Sistem

\begin{abstract}
This research had done base on case study in the feeder of substation $20 \mathrm{kV}$ Jababeka. Existing data showed that condition is well with not too long differential, over all setting on the Overcurrent Relay (OCR) - Ground Fault Relay (GFR) in the field is well. From calculated result can be seem that current of short circuit disturb is influenced by distance between disturbance points. Using over current relay has important purpose in the protection of electricity system. The qualification need setting minimum time of over current relay in the feeder not less than 0.3 second. This consider to the relay will not in trip condition in rush current from distribution transformator that has been connected in the distribution system when the feeder starts operated. Starting time for relay in the feeder is faster than work time in the incoming side with average time about 0.4 second for one phase disturbance side. But for three phase and two phase disturbance side, work time relay has interval time about 0.4 second and than increase with average increament about 0.1 second when transmission line is longer (from distance aspects about 0\%, 25\%, 50\%, 75\% and 100\%).
\end{abstract}

Keywords: Coordination, Relay, OCR, GFR, System Reliabilty

\section{PENDAHULUAN}

Kegagalan pada instalasi sistem tenaga listrik tidak mungkin dapat dihindari, untuk mengurangi kerusakan dan memperkecil daerah gangguan maka dibutuhkan sistem proteksi. Khususnya pada saluran distribusi, gangguan yang mungkin terjadi sebagian besar adalah gangguan hubung singkat, baik hubung singkat tiga fasa, antar fasa 
atau hubung singkat antara fasa dengan tanah Salah satu alat yang termasuk sistem proteksi tersebut dinamakan relai. Relai mendeteksi adanya gangguan dalam sistem tenaga listrik dan memberikan informasi secara otomatis kepada pemutus tenaga agar memisahkan secepat mungkin peralatan listrik yang dilindungi dengan gangguan. Sebagai langkah utama dalam mengatasi adanya gangguan, khususnya pada saluran distribusi biasanya dipakai selain relai jarak yaitu relai arus lebih dan relai gangguan tanah. Dalam fungsinya sebagai sistem proteksi, evaluasi kinerja relai arus lebih atau over relay current (OCR) dan relai gangguan tanah atau ground fault relay (GFR) tersebut harus dilakukan secara kontinyu. Keandalan sebuah sistem proteksi sangat dituntut demi terjaganya kontinyuitas penyaluran enegri listrik. Untuk itu diperlukan koordinasi antar komponen penunjang sistem proteksi. Komponen proteksi yang penting diantaranya over current relay (OCR) dan ground fault relay (GFR).

\subsection{Tujuan}

melakukan analisis koordinasi antara over current relay (OCR) dan ground fault relay (GFR) berdasarkan studi kasus di feeder Gardu Induk 20 kV Jababeka. Serta meningkatkan kualitas kerja relai dengan kriteria nilai selektifitas yang tinggi dan meningkatkan performance relai.

\subsection{Rumusan Masalah}

Bagaimana koordinasi antara over current relay (OCR) dan ground fault relay (GFR) di feeder gardu induk $20 \mathrm{kV}$ Jababeka agar terciptanya keandalan sistem dalam penyaluran energi. Analisa yang dilakukan hanya sebatas pada jaringan distribusi sistem radial.

\section{METODELOGI}

\subsection{Sistem Proteksi}

Sistem proteksi mengurangi akibat gangguan dengan memisahkan bagian sistem yang terganggu dengan bagian sistem yang lain agar bagian sistem yang lain itu dapat terus bekerja. Sistem proteksi berfungsi untuk:

- Mendeteksi gangguan.
- Melindungi dan mengamankan manusia (operator) dari bahaya yang timbul karena adanya arus listrik.

- Melindungi semua peralatan sistem dan mengamankan secepat mungkin dari dari gangguan yang terjadi.

- Dengan koordinasi pemutus beban (circuit breaker) mencegah meluasnya gangguan, mengisolir, memadamkan dan memulihkan kembali sistem setelah gangguan berakhir atau berhenti.

- Menjaga kontinyuitas dan stabilitas daya.

\subsubsection{Pembagian daerah proteksi}

Suatu sistem tenaga listrik dibagi ke dalam seksiseksi yang dibatasi oleh PMT. Tiap seksi memiliki relai pengaman dan memiliki daerah pengamanan (Zone of Protection). Bila terjadi gangguan, maka relai bekerja mendeteksi gangguan dan PMT trip. Gambar berikut ini dapat menjelaskan tentang konsep pembagian daerah proteksi

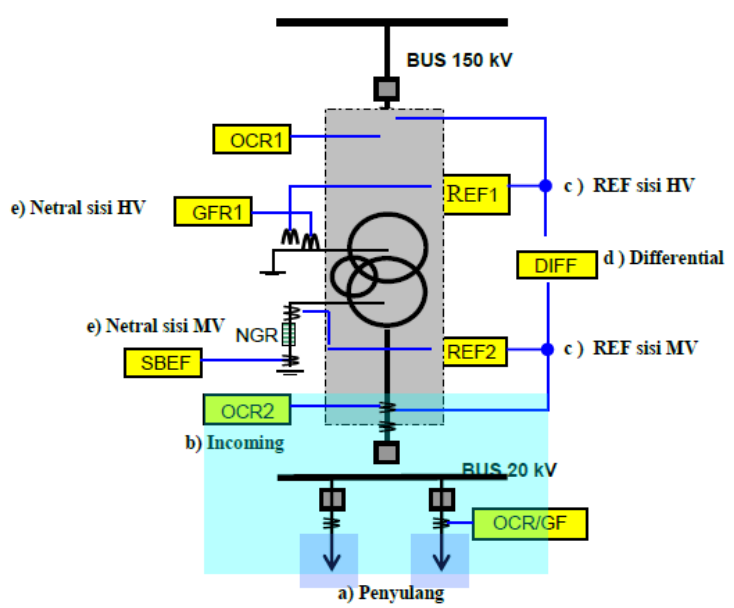

Gambar 1. Skema Sistem Proteksi

Pada gambar di atas dapat dilihat bahwa daerah proteksi pada sistem tenaga listrik dibuat bertingkat dimulai dari pembangkit, gardu induk, saluran distribusi primer sampai ke beban. Garis putus-putus menunjukkan pembagian sistem tenaga listrik ke dalam beberapa daerah proteksi. Masing-masing daerah memiliki satu atau beberapa komponen sistem daya disamping dua buah pemutus rangkaian. Setiap pemutus dimasukkan ke dalam dua daerah proteksi berdekatan. 
Batas setiap daerah menunjukkan bagian sistem yang bertanggung jawab untuk memisahkan gangguan yang terjadi di daerah tersebut dengan sistem lainnya. Aspek penting lain yang harus diperhatikan dalam pembagian daerah proteksi adalah bahwa daerah yang saling berdekatan harus saling tumpang tindih (overlap), hal ini dimaksudkan agar tidak ada sistem yang dibiarkan tanpa perlindungan. Pembagian daerah proteksi ini bertujuan agar daerah yang tidak mengalami gangguan tetap dapat beroperasi dengan baik sehingga dapat mengurangi daerah terjadinya pemadaman.

\subsubsection{Persyaratan Sistem Proteksi}

\section{Keterandalan (Reliability)}

Pada kondisi normal (tidak ada gangguan) relay tidak bekerja. Jika terjadi gangguan maka relay tidak boleh gagal bekerja dalam mengatasi gangguan. Kegagalan kerja relay dapat mengakibatkan alat yang diamankan rusak berat atau gangguannya meluas sehingga daerah yang mengalami pemadaman semakin luas. Relay tidak boleh salah kerja, artinya relay yang seharusnya tidak bekerja, tetapi bekerja. Hal ini menimbulkan pemadaman yang tidak seharusnya dan menyulitkan analisa gangguan yang terjadi. Keandalan relay pengaman ditentukan dari rancangan, pengerjaan, beban yang digunakan, dan perawatannya.

2 Selektivitas (Selectivity)

Selektivitas berarti relay harus mempunyai daya beda (discrimination), sehingga mampu dengan tepat memilih bagian yang terkena gangguan. Kemudian relay bertugas mengamankan peralatan. Relay mendeteksi adanya gangguan dan memberikan perintah untuk membuka pemutus tenaga dan memisahkan bagian yang terganggu. Bagian yang tidak terganggu jangan sampai dilepas dan masih Jika terjadi pemutusan hanya terbatas pada daerah yang terganggu.

3 Sensitivitas (Sensitivity)

Relay harus mempunyai kepekaan yang tinggi terhadap besaran minimal (kritis) sebagaimana direncanakan. Relay harus dapat bekerja pada awalnya terjadinya gangguan. Oleh karena itu, gangguan lebih mudah diatasi pada awal kejadian. Hal ini memberi keuntungan dimana kerusakan peralatan yang harus diamankan menjadi kecil. Namun demikian, relay juga harus stabil.

\section{Kecepatan Kerja}

Relay pengaman harus dapat bekerja dengan cepat. Jika ada gangguan, misalnya isolasi bocor akibat adanya gangguan tegangan lebih terlalu lama sehingga peralatan listrik yang diamankan dapat mengalami kerusakan. Namun demikian, relay tidak boleh bekerja terlalu cepat (kurang dari $10 \mathrm{~ms}$ ). Disamping itu, waktu kerja relay tidak boleh melampaui waktu penyelesaian kritis (critical clearing time). Pada sistem yang besar atau luas, kecepatan kerja relay pengaman mutlak diperlukan karena untuk menjaga kestabilan sistem agar tidak terganggu. Hal ini untuk mencegah relay salah kerja karena transient akibat surja petir.

\section{Ekonomis}

Satu hal yang harus diperhatikan sebagai persyaratan relay pengaman adalah masalah harga atau biaya. Relay tidak diaplikasikan dalam sistem tenaga listrik, jika harganya sangat mahal. Persyaratan reliabilitas, sensitivitas, selektivitas dan kecepatan kerja relay hendaknya tidak menyebabkan harga relay tersebut menjadi mahal.

\subsection{Relay Proteksi}

Rele proteksi adalah susunan peralatan yang direncanakan untuk dapat merasakan atau mengukur adanya gangguan atau mulai merasakan tenaga listrik dan segera otomatis memberi perintah untuk membuka pemutus tenaga untuk memisahkan peralatan atau bagian dari sistem proteksi yang terganggu dan memberikan isyarat berupa lampu atau bel. Rele proteksi dapat merasakan adanya gangguan pada peralatan yang diamankan dengan mengukur atau membandingkan besaranbesaran yang diterimanya, misalnya arus, tegangan, daya, sudut fase, frekuensi, impedansi dan sebagainya, dengan besaran yang telah 
ditentukan kemudian mengambilnya keputusan untuk seketika ataupun dengan perlambatan waktu membuka pemutus tenaga.

Fungsi rele proteksi:

a. Merasakan, mengukur dan menentukan bagian sistem yang terganggu serta memisahkan secepatnya sehingga sistem lain yang tidak terganggun dapat beroperasi normal.

b. Mengurangi kerusakan yang lebih parah dari peralatan yang terganggu

c. Mengurangi pengaruhnya gangguan terhadap bagian sistem yang tidak terganggu di dalam sistem tersebut serta mencegah meluasnya gangguan.

d. Memperkecil bahaya bagi manusia

Dari fungsinya diatas, adakalanya ada kegagalan dalam pengaman rele proteksi. Hal-hal yang dapat menimbulkan kegagalan pengaman dapat di kelompokan sebagai berikut:

a. Kegagalan pada rele itu sendiri

b. Kegagalan suplai arus dan/atau tegangan ke rele tegangannya rangkaian suplai ke rele dari trafo terbuka atau terhubung singkat.

c. Kegagalan sistem suplai arus searah untuk triping pemutus tenaga. Hala yang dapat menyebabkan nya antara lain baterai lemah karena kurang perawatan, terbukanya atau terhubung singkat rangkaian arus searah.

d. Kegagalan pemutus tenaga. Kegagalan ini dapat disebabkan karena kumparan trip tidak menerima suplai, kerusakan mekanis ataupun kegagalan pemutusan arus kemampuan dari pemutus tenaganya.

Karena ada kemungkinan kegagalan pada sistem pengaman maka arus dapat diatasi yaitu dengan penggunaan pengaman cadangan (Back Up Protection). Dengan demikian pengaman menurut fungsinya dapat dikelompokan menjadi:

a. Pengaman utama yang pada umumnya selektif dan cepat dan malah jenis tertentu mempunyai sifat selektif mutlak misalnya rele diferensial

b. Pengaman cadangan, umumnya mempunyai perlambatan waktu hal ini untuk memberikan kesempatan kepada pengaman utama bekerja terlebih dahulu, dan jika pengaman utama gagal, baru pengaman cadangan bekerja dan rele ini tidak seselektif pengaman utama

Proteksi terdiri dari seperangkat peralatan yang merupakan sistem yang terdiri dari komponenkomponen berikut:

1. Relay, sebagai alat perasa untuk mendeteksi adanya gangguan yang selanjutnya memberi perintah trip kepada Pemutus Tenaga (PMT).

2. Trafo arus dan/atau trafo tegangan sebagai alat yang mentransfer besaran listrik primer dari sistem yang diamankan ke relay (besaran listrik sekunder).

3. Pemutus Tenaga (PMT) untuk memisahkan bagian sistem yang terganggu.

4. Batere beserta alat pengisi (batere charger) sebagai sumber tenaga untuk bekerjanya relay, peralatan bantu triping.

5. Pengawatan (wiring) yang terdiri dari sisrkit sekunder (arus dan/atau tegangan), sirkit triping dan sirkit peralatan bantu.

Secara garis besar bagian dari relay proteksi terdiri dari tiga bagian utama, seperti pada blok diagram dibawah ini :

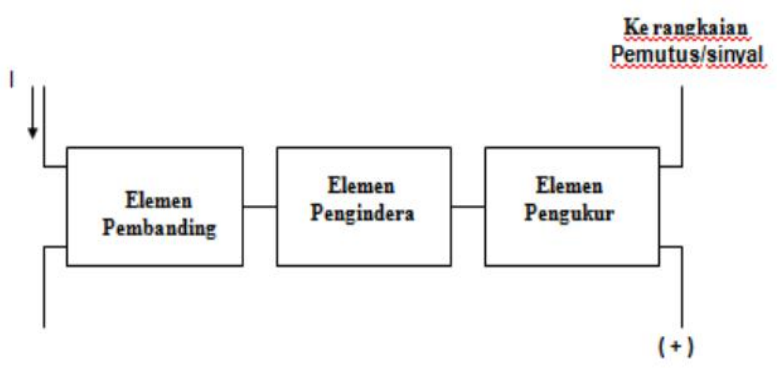

Gambar 2. Blok diagram utama rele proteksi

Masing-masing elemen mempunyai fungsi sebagai berikut:

- Elemen pengindera

Elemen ini berfungsi untuk merasakan besaran-besaran listrik, seperti arus, tegangan, frekuensi, dan sebagainya tergantung relay yang dipergunakan. Pada bagian ini besaran yang masuk akan dirasakan keadaannya, apakah keadaan yang diproteksi itu mendapatkan gangguan atau dalam keadaan normal, untuk 
selanjutnya besaran tersebut dikirimkan ke elemen pembanding.

- Elemen pembanding

Elemen ini berfungsi menerima besaran setelah terlebih dahulu besaran itu diterima oleh elemen oleh elemen pengindera untuk membandingkan besaran listrik pada saat keadaan normal dengan besaran arus kerja relay.

- Elemen pengukur/penentu

Elemen ini berfungsi untuk mengadakan perubahan secara:

\subsection{Gangguan Hubung Singkat}

Gangguan hubung singkat adalah gangguan yang terjadi karena adanya kesalahan antara bagian-bagian yang bertegangan. Gangguan hubung singkat dapat juga terjadi akibat adanya isolasi yang tembus atau rusak karena tidak tahan terhadap tegangan lebih, baik yang berasal dari dalam maupun yang berasal dari luar. Gangguan yang mengakibatkan hubung singkat dapat menimbulkan arus yang jauh lebih besar dari pada arus normal. Bila gangguan hubung singkat dibiarkan berlangsung dengan lama pada suatu sistem daya, banyak pengaruh-pengaruh yang tidak diinginkan yang terjadi. Berikut ini akibat yang ditimbulkan gangguan hubung singkat:

a. Berkurangnya batas-batas kestabilan untuk sistem daya.

b. Rusaknya perlengkapan yang dekat dengan gangguan yang disebabkan oleh arus tak seimbang, atau tegangan rendah yang ditimbulkan oleh hubung singkat.

c. Ledakan yang mungkin terjadi pada peralatan yang mengandung minyak isolasi sewaktu terjadinya suatu hubung singkat.

d. Terpecahnya keseluruhan daerah pelayanan sistem daya itu oleh suatu rentetan tindakan pengamanan yang diambil oleh sistem pengamanan yang berbedabeda; kejadian ini di kenal sebagai "cascading".

\section{PEMBAHASAN DAN ANALISA}

\subsection{Pembahasan}

\subsubsection{Over Current Relay (OCR)}

Proteksi arus lebih adalah proteksi terhadap perubahan parameter arus yang sangat besar dan terjadi pada waktu yang cepat, yang disebabkan oleh hubung singkat. Pada proteksi arus lebih ini, relai pick-up jika besar arus melebihi nilai seting.

Relai arus lebih terdapat beberapa karakteristik waktu yang dikelompokkan menjadi tiga jenis:

1. Relai Arus Lebih Seketika (Instantaneus)

2. Relai Arus Lebih Waktu Tertentu

3. Relai Arus Lebih Terbalik (Inverse)

\section{a. Rele Waktu Seketika (Instantaneous Relay)} Relay yang bekerja seketika (tanpa waktu tunda) ketika arus yang mengalir melebihi nilai settingnya, relay bekerja dalam waktu beberapa mili detik (10 - $20 \mathrm{~ms})$. Dapat kita lihat pada gambar dibawah ini.
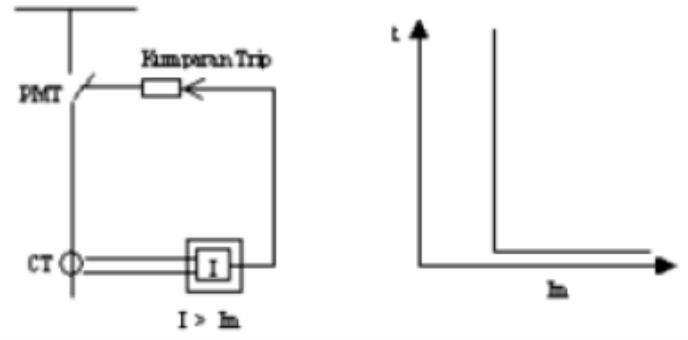

Gambar 3. Karakteristik Instantaneous Relay

Relay ini jarang berdiri sendiri tetapi umumnya dikombinasikan dengan relay arus lebih dengan karakteristik yang lain.

\section{b. Relay Arus Lebih Waktu Tertentu (Definite Time Relay)}

Relay ini akan memberikan perintah pada PMT pada saat terjadi gangguan hubung singkat dan besarnya arus gangguan melampaui settingnya (Is), dan jangka waktu kerja relay mulai pick up sampai kerja relay diperpanjang dengan waktu tertentu tidak tergantung besarnya arus yang mengerjakan relay, lihat gambar dibawah ini.
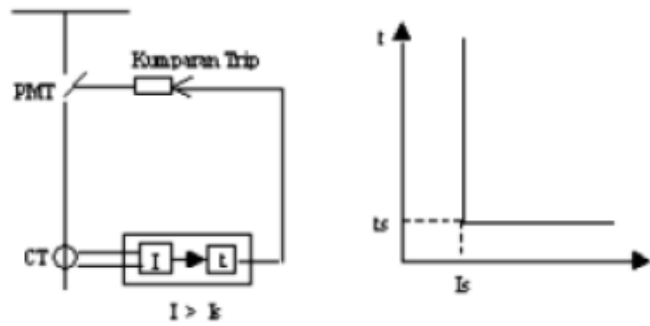

Gambar 4. Karakteristik Defenite Time Relay 


\section{c. Relay arus lebih waktu terbalik (Inverse Time Relay)}

Relay ini akan bekerja dengan waktu tunda yang tergantung dari besarnya arus secara terbalik (inverse time), makin besar arus makin kecil waktu tundanya. Karakteristik ini bermacammacam dan setiap pabrik dapat membuat karakteristik yang berbeda-beda.
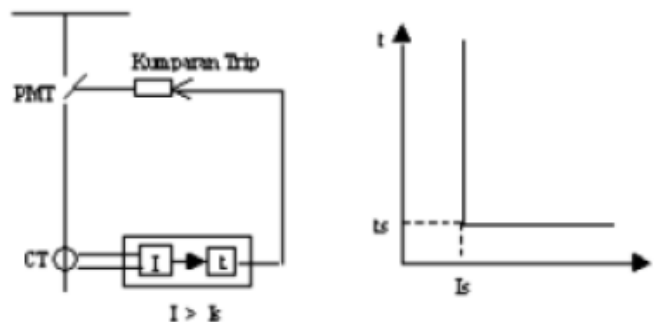

Gambar 4. Karakteristik Relay Arus Lebih Waktu Terbalik (Inverse Time Relay)

\section{d. Prinsip Kerja OCR}

Prinsip kerja over current relay adalah berdasarkan adanya arus lebih yang dirasakan relai, baik disebabkan adanya gangguan hubung singkat atau overload (beban lebih) untuk kemudian memberikan perintah trip ke PMT sesuai dengan karakteristik waktunya.

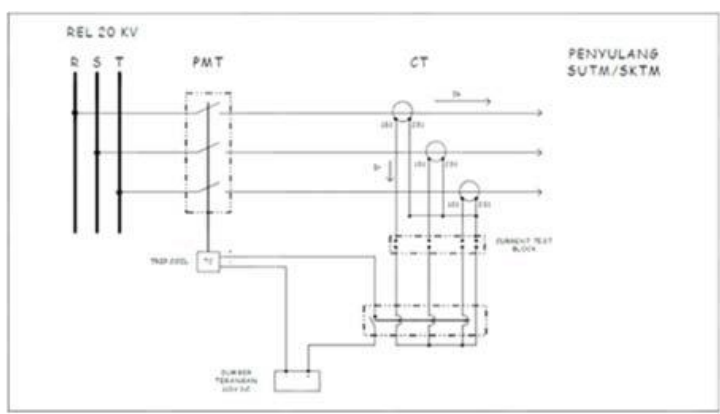

Gambar 5. Rangkaian Pengawatan OCR

Pemutus Tenaga (PMT)

Pemutus tenaga (PMT) atau lebih dikenal dengan istilah Circuit Breaker (CB) merupakan suatu piranti saklar mekanik yang secara otomatis membuka atau memutuskan rangkaian listrik apabila terjadi ketidaknormalan pada suatu system tanpa adanya kerusakan.

Pemutus tenaga terdiri atas kontak-kontak yang dialiri arus listrik atau lebih dikenal dengan elektroda. Pada kondisi normal eletroda- elektroda tersebut dalam kondisi terhubung, sebaliknya pada kondisi abnormal maka elektroda-elektroda terpisah dan memutuskan hubungan listrik dari satu sisi ke sisi yang lainnya

\section{e. Pengaman Pada Relay Arus Lebih}

Pada relay arus lebih memiliki 2 jenis pengamanan yang berbeda antara lain:

- Pengamanan hubung singkat fasa. Relay mendeteksi arus fasa. Oleh karena itu, disebut pula "Relay fasa". Karena pada relay tersebut dialiri oleh arus fasa, maka settingnya (Is) harus lebih besar dari arus beban maksimum. Ditetapkan Is $=1,2 \mathrm{x}$ In (In = arus nominal peralatan terlemah).

- Pengamanan hubung tanah. Arus gangguan satu fasa tanah ada kemungkinan lebih kecil dari arus beban, ini disebabkan karena salah satu atau dari kedua hal berikut:

Gangguan tanah ini melalui tahanan gangguan yang masih cukup tinggi. Pentanahan netral sistemnya melalui impedansi/tahanan yang tinggi, atau bahkan tidak ditanahkan Dalam hal demikian, relay pengaman hubung singkat (relay fasa) tidak dapat mendeteksi gangguan tanah tersebut. Supaya relay sensitive terhadap gangguan tersebut dan tidak salah kerja oleh arus beban, maka relay dipasang tidak pada kawat fasa melainkan kawat netral pada sekunder trafo arusnya. Dengan demikian relay ini dialiri oleh arus netralnya, berdasarkan komponen simetrisnya arus netral adalah jumlah dari arus ketiga fasanya. Arus urutan nol dirangkaian primernya baru dapat mengalir jika terdapat jalan kembali melalui tanah (melalui kawat netral).

\section{f. Fungsi Dan Penggunaan}

Relay arus lebih tak berarah dan relay hubung tanah tak terarah atau cukup disebut relay arus lebih dan relay hubung tanah. Relay ini berfungsi sebagai pengaman terhadap gangguan arus hubung singkat fasa-fasa maupun fasa tanah dan dapat digunakan sebagai:

- Pengaman utama penyulang (jaringan tegangan menengah).

- Pengaman cadangan pada trafo, generator dan transmisi. 
- Pengamanan utama untuk sistem tenaga listrik yang kecil dan radial.

- Pengamanan utama motor listrik yang kecil.

\section{g. Perhitungan Koordinasi Rele Arus Lebih}

Pada tahap selanjutnya, hasil perhitungan arus gangguan hubung singkat, dipergunakan untuk nilai setelan arus lebih, terutama nilai setelan TMS (Time Multiple Setting) dari rele arus lebih dengan karakteristik jenis inverse.

Disamping itu setelah nilai setelan rele diperoleh, nilai arus gangguan hubung singakat pada setiap lokasi gangguan yang diasumsikan, dipakai untuk memeriksa rele arus lebih itu, apakah masih dapat dinilai selektif atau nilai setelan harus dirubah kenilai lain yang memberikan kerja rele yang lebih selektif, atau didapatkan kerja selektifitas yang optimum (Rele bekerja tidak bekerja terlalu lama tetapi menghasilkan selektifitas yang baik).

Sedangkan setelan arus dari rele arus lebih dihitung berdasarkan arus beban yang mengalir dipenyulang atau incoming feeder, artinya :

a. Untuk rele arus lebih yang terpasang dipenyulang keluar (Outgoing Feeder) dihitung berdasarkan arus beban maksimum (Beban Puncak) yang mengalir dipenyulang tersebut.

b. Untuk rele arus lebih yang terpasang dipenyulang masuk (incoming feeder) dihitung berdasarkan arus nominal transformator tenaga.

Sesuai British standard untuk:

- Rele inverse biasa disett sebesar 1,05 s/d 1,3 IBeban,

- Sedangkan rele definite disett sebesar 1,2 s/d 1,3 IBeban.

Persyaratan lain yang harus dipenuhi adalah penyetelan waktu minimum dari rele arus lebih (terutama di penyulang) tidak lebih kecil dari 0,3 detik. Pertimbangan ini diambil agar rele tidak sampai trip lagi akibat arus inrush dari trafo distribusi yang memang sudah tersambung dijaringan distribusi, sewaktu PMT penyulang tersebut dioperasikan.

\section{h. Setting OCR}

Arus setting untuk relai OCR baik pada sisi primer maupun pada sisi sekunder transformator tenaga adalah:

Iset (prim) = 1,05 $\mathrm{x}$ Inom trafo

Nilai tersebut adalah nilai primer, untuk mendapatkan nilai setelan sekunder yang dapat disetkan pada relay OCR, maka harus dihitung dengan menggunakan ratio trafo (CT) yang terpasang pada sisi primer maupun sisi sekunder transfomator tenaga.

$$
\mathrm{I}_{\text {set }}(\mathrm{sek})=\mathrm{I}_{\text {set }}(\text { prim }) \times \frac{1}{\text { Ratio } C T}
$$

\section{i. Setelan Time Multiple Setting (TMS)}

Setelan TMS dan setelan waktu rele pada jaringan distribusi menggunakan standard inverse yang dihitung menggunakan rumus kurva waktu vs arus, dalam hal ini juga diambil persamaan kurva arus waktu dari standard british, sebagai berikut :

$$
\text { TMS }=\frac{\mathrm{t} \times\left[\left[\frac{\mathrm{I}_{\text {Fault }}}{\mathrm{I}_{\mathrm{Set}}}\right]^{\alpha}-1\right]}{\beta}
$$

Dan

$$
\mathrm{t}=\frac{\beta \mid \times \mathrm{TMS}}{\left(\frac{\mathrm{I}_{\text {Fault }}}{\mathrm{I}_{\text {Set }}}\right)^{\alpha}-1}
$$

Dimana :

$\mathrm{t} \quad=$ Waktu Trip (Detik)

TMS = Time Multiple Setting

Ifault = Arus Gangguan Hubung Singkat (Amp)

- Setelan OCR (Inverse) diambil arus gangguan hubung singkat terbesar.

- Setelan GFR (Inverse) diambil arus gangguan hubung singkat terkecil.

Iset $=$ Arus Setting Sisi Primer (Amp)

- Setelan OCR (inverse) diambil (BS) 1,05 s/d 1,3 IBeban

- Setelan GFR (inverse) diambil 6\% s/d 12\% Ifault hubung singkat 1 fasa terkecil.

$\alpha, \beta=$ Konstanta.

Table 1. Faktor dan tergantung pada kurva arus vs waktu 


\begin{tabular}{|c|c|c|}
\hline Nama Kurva & $\boldsymbol{\alpha}$ & $\boldsymbol{\beta}$ \\
\hline Standard Inverse & 0,02 & 0,14 \\
\hline Very Inverse & 1 & 13,2 \\
\hline Extremely Inverse & 2 & 80 \\
\hline Long Inverse & 1 & 120 \\
\hline
\end{tabular}

\subsubsection{Ground Fault Relay ( GFR )}

Ground Fault Relay (GFR) pada dasarnya mempunyai prinsip kerja yang sama denga relai arus lebih (OCR) namun memiliki perbedaan dalam kegunaanya. GFR mendeteksi melalui binary input yang ada pada relai sehingga memerintahkan binary output agar memberikan perintah jika adanya hubungan singkat ke tanah.

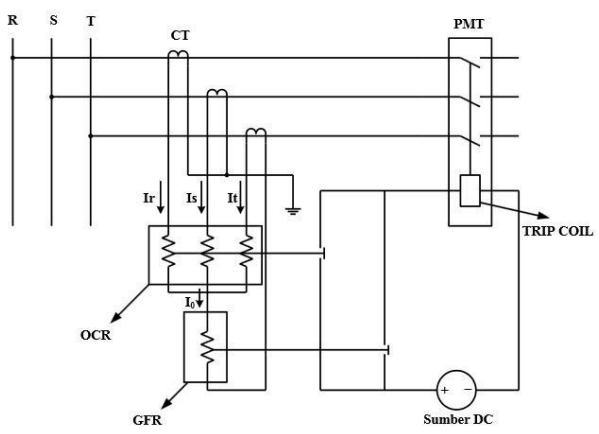

Gambar 6. Rangkaian GFR

\section{a. Prinsip Kerja GFR}

Pada kondisi normal beban seimbang Ir, Is, It sama besar, sehingga pada kawat netral tidak timbul arus dan relai hubung tanah tidak di aliri arus. Bila terjadi ketidakseimbangan arus atau terjadi gangguan hubung singkat ke tanah, maka akan timbul arus urutan nol pada kawat netral, sehingga relai hubung tanah akan bekerja.

\section{b. Setting GFR}

Arus setting untuk relai OCR baik pada sisi primer maupun pada sisi sekunder transformator tenaga adalah:

Iset $($ Prim $)=\mathbf{1 0} \% \times$ Inominal trafo

Untuk menghitung setting arus untuk sisi sekunder yaitu:

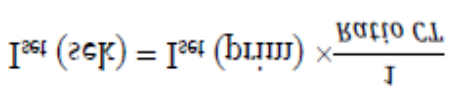

\section{c. Setelan waktu (TMS)}

Hasil perhitungan arus gangguan hubung singkat, selanjutnya digunakan untuk menentukan nilai setelan waktu kerja relay
(TMS). Sama halnya dengan relay OCR, relay GFR menggunakan rumus penyetingan TMS yang sama dengan relay OCR. Tetapi waktu kerja relay yang diinginkannya berbeda.

Menentukan nilai TMS yang akan disetkan pada relay GFR, transformator tenaga diambil arus hubung singkat 1 fasa ke tanah dengan rumus (Pandjaitan, $2012: 72$ ) :

$$
\mathrm{Tms}=\frac{t x\left[\frac{I_{\text {fault }}}{I_{\text {set }}}\right]^{0,02}-1}{0,14}
$$

Dimana :

Tms = Setting waktu relay $(\mathrm{s})$

$\mathrm{t}=$ Waktu kerja relay

Iset $\quad=$ Arus setting primer $(\mathrm{A})$

Ifault = Arus gangguan hubung singkat

\subsection{Analisa}

\subsubsection{Arus Hubung Singkat}

Gangguan hubung singkat yang mungkin terjadi di dalam jaringan (sistem kelistrikan) ada 3, yaitu:

a. gangguan hubung singkat 3 fasa

b. gangguan hubung singkat 2 fasa

c. gangguan hubung singkat 1 fasa.

Perhitungan gangguan hubung singkat ini dihitung besarnya berdasarkan panjang penyulang, yaitu diasumsikan terjadi di $25 \%$, $50 \%, 75 \%$ dan $100 \%$ panjang penyulang.

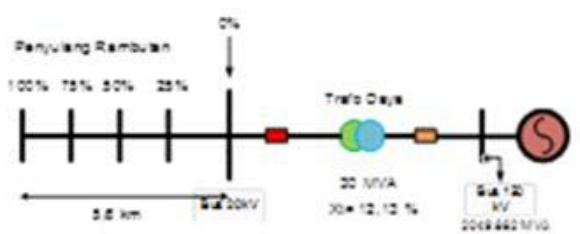

Gambar 7. Gangguan Hubungan Singkat

\subsubsection{Hasil Perhitungan Arus Hubung Singkat}

Tabel 2. Hasil Perhitungan Arus Gangguan Hubung Singkat

\begin{tabular}{|c|c|c|c|c|}
\hline \multirow{2}{*}{$\begin{array}{c}\text { Panjang } \\
\text { Penyulang } \\
(\%)\end{array}$} & \multirow{2}{*}{ Jarak (m) } & \multicolumn{4}{|c|}{ Arus Hubung Singkat (A) } \\
\cline { 3 - 5 } & & 3 fasa & 2 fasa & 1 fasa \\
\hline 0 & 0 & 6372,165 & 5518,459 & 797,3515 \\
\hline 25 & 1400 & 5104,678 & 4420,769 & 758,6516 \\
\hline 50 & 2800 & 4241,428 & 3673,162 & 721,9917 \\
\hline 75 & 4200 & 3620,998 & 3135,927 & 687,5387 \\
\hline 100 & 5600 & 3155,953 & 2733,099 & 655,3079 \\
\hline
\end{tabular}




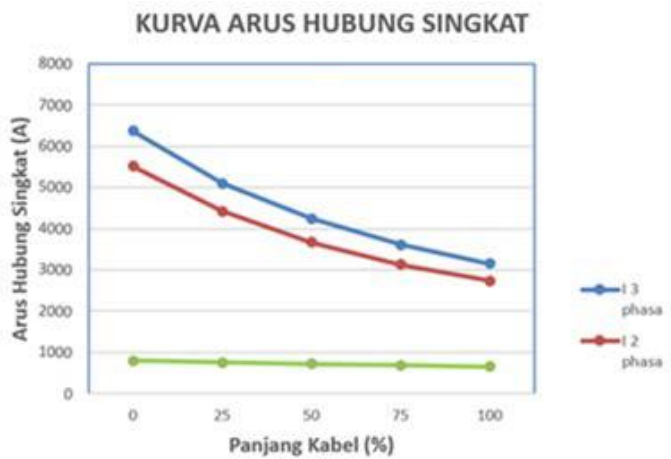

Gambar 8. Kurva Arus Hubung singkat

Dari tabel diatas bahwa besarnya arus gangguan hubung singkat dipengaruhi jarak titik gangguan, semakin jauh jarak titik gangguan maka semakin kecil arus gangguan hubung singkatnya dan sebaliknya. Selain itu dapat dilihat bahwa arus gangguan hubung singkat terbesar yaitu pada arus gangguan hubung singkat 3 fasa, apabila ditinjau dari gangguan terhadap fasa.

\subsubsection{Hasil Perhitungan Waktu Kerja Relay}

\section{a. Waktu Kerja Relay 3 Fasa}

Tabel 3. Hasil Perhitungan Waktu Kerja Relai 3 Relai Fasa

\begin{tabular}{|c|c|c|c|}
\hline $\begin{array}{c}\text { Lokasi } \\
\text { Gangguan (\% } \\
\text { panjang) }\end{array}$ & $\begin{array}{c}\text { Waktu kerja relay } \\
\text { incoming (detik) }\end{array}$ & $\begin{array}{c}\text { Waktu kerja } \\
\text { relai penyulang } \\
\text { (detik) }\end{array}$ & $\begin{array}{c}\text { Selisih w aktu } \\
\text { (Grading Time) } \\
\text { (detik) }\end{array}$ \\
\hline $0 \%$ & 0,698 & 0,299 & 0,399 \\
\hline $25 \%$ & 0,789 & 0,323 & 0,466 \\
\hline $50 \%$ & 0,886 & 0,346 & 0,54 \\
\hline $75 \%$ & 0,989 & 0,367 & 0,622 \\
\hline $100 \%$ & 1,1 & 0,388 & 0,712 \\
\hline
\end{tabular}

WAKTU KERJA RELAI PADA GANGGUAN 3 PHASA

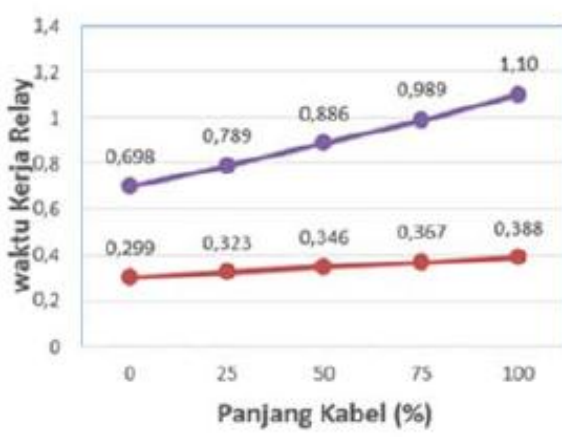

$\rightarrow$ t peryulang $20 \mathrm{kV}$ (detik) - incoming o kV (detik)

Gambar 9. Kurva Pemeriksaan Waktu kerja Relay untuk Ganggguan 3 Fasa

\section{b. Waktu Kerja Relai 2 Fasa}

Tabel 4. Hasil Perhitungan Waktu Kerja Relai 2 Fasa

\begin{tabular}{|c|c|c|c|}
\hline $\begin{array}{c}\text { Lokasi } \\
\text { Gangguan (\% } \\
\text { panjang) }\end{array}$ & $\begin{array}{c}\text { Waktu kerja } \\
\text { relay incoming } \\
\text { (detik) }\end{array}$ & $\begin{array}{c}\text { Waktu kerja } \\
\text { relai penyulang } \\
\text { (detik) }\end{array}$ & $\begin{array}{c}\text { Selisih waktu } \\
\text { (Grading Time) } \\
\text { (detik) }\end{array}$ \\
\hline $0 \%$ & 0,755 & 0,315 & 0,44 \\
\hline $25 \%$ & 0,863 & 0,34 & 0,523 \\
\hline $50 \%$ & 0,979 & 0,365 & 0,614 \\
\hline $75 \%$ & 1,105 & 0,389 & 0,716 \\
\hline $100 \%$ & 1,246 & 0,413 & 0,833 \\
\hline
\end{tabular}

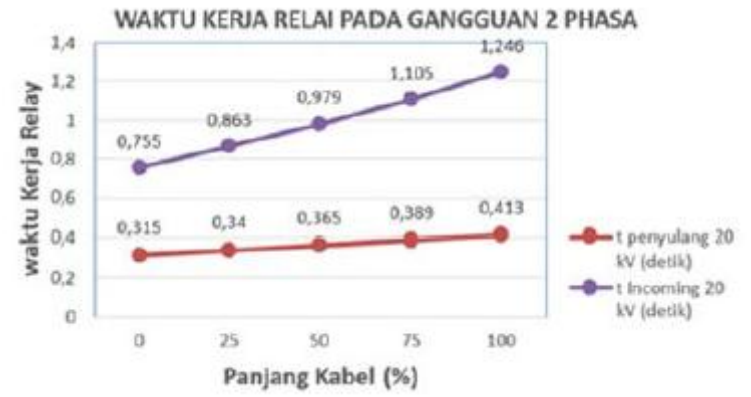

Gambar 10. Kurva Pemeriksaan Waktu kerja Relay untuk Ganggguan 2 Fasa

\section{c. Waktu Kerja Relai 1 Fasa}

Tabel 5. Hasil Perhitungan Waktu Kerja Relai 1 Fasa

\begin{tabular}{|c|c|c|c|}
\hline $\begin{array}{c}\text { Lokasi } \\
\text { Gangguan (\% } \\
\text { panjang) }\end{array}$ & $\begin{array}{c}\text { Waktu kerja } \\
\text { relay incoming } \\
\text { (detik) }\end{array}$ & $\begin{array}{c}\text { Waktu kerja } \\
\text { relai penyulang } \\
\text { (detik) }\end{array}$ & $\begin{array}{c}\text { Selisih waktu } \\
\text { (Grading Time) } \\
\text { (detik) }\end{array}$ \\
\hline $0 \%$ & 0,698 & 0,3 & 0,398 \\
\hline $25 \%$ & 0,711 & 0,307 & 0,404 \\
\hline $50 \%$ & 0,725 & 0,313 & 0,412 \\
\hline $75 \%$ & 0,739 & 0,32 & 0,419 \\
\hline $100 \%$ & 0,754 & 0,326 & 0,428 \\
\hline
\end{tabular}

WAKTU KERJA RELAI PADA GANGGUAN 1 PHASA

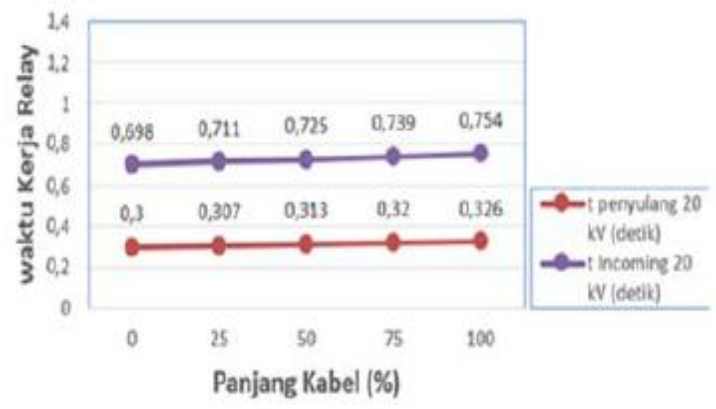


Gambar 11. Kurva Pemeriksaan Waktu kerja Relay untuk Ganggguan 1 Fasa

\section{c. Perbandingan Hasil Perhitungan Arus Hubung Singkat}

Tabel 6. Hasil Perhitungan Arus Hubung Singkat Penyulang Rambutan

\begin{tabular}{|c|c|c|c|c|}
\hline \multirow{2}{*}{$\begin{array}{c}\text { Panjang } \\
\text { Penyulang } \\
(\%)\end{array}$} & \multirow{2}{*}{ Jarak (m) } & \multicolumn{3}{|c|}{ Arus Hubung Singlat (A) } \\
\cline { 3 - 5 } & & 3 Asa & 2 fasa & 1 Asa \\
\hline 0 & 0 & 6372,165 & 5518,459 & 797,3515 \\
\hline 25 & 1400 & 5104,678 & 4420,769 & 758,6516 \\
\hline
\end{tabular}

\begin{tabular}{|c|c|c|c|c|}
\hline 50 & 2800 & 4241,428 & 3673,162 & 721,9917 \\
\hline 75 & 4200 & 3620,998 & 3135,927 & 687,5387 \\
\hline 100 & 5600 & 3155,953 & 2733,099 & 655,3079 \\
\hline
\end{tabular}

Tabel 7. Hasil Perhitungan Arus Hubung Singkat Existing Penyulang Rambutan

\begin{tabular}{|c|c|c|c|c|}
\hline \multirow{2}{*}{ Panjang Penyulang (\%) } & \multirow{2}{*}{ Jarak (m) } & \multicolumn{3}{|c|}{ Arus Hubung Singkat (A) } \\
\cline { 3 - 5 } & & 3 fasa & 2 fasa & 1 fasa \\
\hline 0 & 0 & 6255.66 & 5405.8 & 777.1 \\
\hline 25 & 1400 & 4952.388 & 4288.6 & 744.3 \\
\hline 50 & 2800 & 4087.90 & 3540.2 & 712,6 \\
\hline 75 & 4200 & 3.326 .078 & 3014,4 & 683 \\
\hline 100 & 5600 & 3.038 .043 & 2630,8 & 644.04 \\
\hline
\end{tabular}

Dari tabel diatas terlihat adanya perbedaan antara hasil perhitungan dengan realisasi dilapangan hal ini dikarenakan adanya sistem perhitungan yang berbeda maka arus hubung singkat existing lebih kecil jika dibandingkan dengan arus hubung singkat hasil perhitungan. Hal ini disebabkan sistem perhitungan arus hubung singkat existing tidak memperhatikan hubungan trafo yang berada di GI dan hanya melihat belitannya saja.

\section{d. Perbandingan Hasil Perhitungan Setting Time Relay Dengan Data di Lapangan}

Berdasarkan table berikut dapat dianalisa bahwa hasil perhitungan dengan data yang ada di lapangan masih dalam kondisi yang sesuai dengan perbedaan yang tidak terlalu signifikan, sehingga dapat disimpulkan bahwa secara keseluruhan setting Overcurrent Relay dan Ground Fault Relay di sisi penyulang, yang ada di lapangan sudah baik.
Tabel 8. Perbandingan Hasil Perhitungan Dengan Data Lapangan

\begin{tabular}{|c|c|c|c|c|c|}
\hline No & Nama relay & \multicolumn{2}{|c|}{$\begin{array}{c}\text { Data Hasil } \\
\text { perhitungan }\end{array}$} & \multicolumn{2}{|c|}{$\begin{array}{c}\text { Data yang terpasang } \\
\text { di lapangan }\end{array}$} \\
\hline \multirow{3}{*}{1.} & \multirow{3}{*}{$\begin{array}{l}\text { OCR (Sisi } \\
\text { Incoming) }\end{array}$} & TMS & $=0,198$ & TMS & $=0,2$ \\
\hline & & Rasio C & $=1000 / 5$ & Rasio & $=1000 / 5$ \\
\hline & & t kerja & $=0,7$ & t kerja & $=0,71$ \\
\hline \multirow{3}{*}{2.} & \multirow{3}{*}{$\begin{array}{l}\text { GFR (Sisi } \\
\text { Incoming) }\end{array}$} & TMS & $=0,279$ & TMS & $=0,469$ \\
\hline & & Rasio C & $=1000 / 5$ & Rasio & $=1000 / 5$ \\
\hline & & t kerja & $-0,7$ & t kerja & $-1,2$ \\
\hline \multirow{3}{*}{3.} & \multirow{3}{*}{$\begin{array}{l}\text { OCR (Sisi } \\
\text { Penyulang) }\end{array}$} & TMS & $=0,1396$ & TMS & $=0,17$ \\
\hline & & Rasio C & $=300 / 5$ & Rasio & $=300 / 5$ \\
\hline & & t kerja & $-0,3$ & t kerja & $-0,4$ \\
\hline \multirow{3}{*}{4.} & \multirow{3}{*}{$\begin{array}{l}\text { GFR (Sisi } \\
\text { Penyulang) }\end{array}$} & TMS & $=0,11$ & TMS & $=0,11$ \\
\hline & & Rasio C & $=300 / 5$ & Rasio & $=300 / 5$ \\
\hline & & t kerja & $=0,3$ & t kerja & $=0,3$ \\
\hline
\end{tabular}

Karena hasil dari perhitungan tersebut untuk di set kan ke relai Overcurrent Relay dan Ground Fault Relay maka harus disesuaikan dengan taptap yang ada pada relai yang bersangkutan. Sehingga hasilnya tidak akan persis sama dengan hasil perhitungan. Tetapi ada setting relay yang sudah tidak sesuai lagi, yaitu setting GFR disisi incoming, dimana $t=0,279$, dengan kata lain jika terjadi gangguan hubung singkat satu fasa ke tanah, maka relai tersebut akan memerlukan waktu yang lebih lama untuk bekerja. Jadi setting relai GFR sisi Incoming yang ada di lapangan harus di setting kembali untuk didapat nilai timing trip coil yang sesuai standartnya.

\section{PENUTUP}

\subsection{Kesimpulan}

- Dari hasil perhitungan dapat dilihat bahwa besarnya arus gangguan hubung singkat dipengaruhi oleh jarak titik gangguan. Ketika titik jarangan gangguan semakin jauh, maka arus gangguan hubung singkatnya semakin kecil, begitu pula sebaliknya.

- Waktu kerja relai pada penyulang lebih cepat jika dibandingkan dengan waktu kerja pada sisi incoming dengan selisih waktu rata-rata sebesar 0,4 detik untuk sisi gangguan satu fasa. Namun untuk sisi gangguan tiga fasa dan dua fasa, waktu kerja relai memiliki selisih waktu 0,4 detik 
dan berangsur meningkat dengan rata-rata kenaikan 0,1 detik ketika panjang kabel semakin jauh (ditinjau pada jarak 0\%, 25\%, $50 \%, 75 \%$ dan $100 \%)$.

- Hasil perhitungan dengan data existing di lapangan masih dalam kondisi yang sesuai dengan perbedaan yang tidak terlalu jauh, sehingga dapat disimpulkan bahwa secara keseluruhan setting pada Overcurrent Relay (OCR) - Ground Fault Relay (GFR) yang ada di lapangan dalam kondisi baik.

- Berdasarkan hasil penulisan dapat disimpulkan bahwa penggunaan relay arus lebih atau over current relay mempunyai peran yang sangat penting dalam memproteksi system tenaga listrik. Persyaratan yang harus dipenuhi adalah penyetelan waktu minimum dari relay arus lebih (terutama dipenyulang) tidak lebih kecil dari 0,3 detik. Pertimbangan ini diambil agar relay tidak sampai trip lagi Inrush Current dari transformator distribusi yang memang sudah tersambung dijaringan distribusi sewaktu PMT penyulang tersebut dioperasikan.

\subsection{Saran}

- Bagi masyarakat agar pada saat melakukan penyettingan relay harus betul-betul memahami bagaimana cara perhitungan dan koordinasi relay dan system proteksi lainnya, sehingga tidak terjadi kegagalan operasi pada relay tersebut. Karena akan sangat fatal jika relay mengalami kegagalan operasi.

\section{DAFTAR PUSTAKA}

(PERSERO), J. D. (2000). Keandalan Sistem Distribusi. Jakarta: PT. PLN (PERSERO) .

(PERSERO), P. P. (2010). Buku 1 Kriteria Desain Enjinering Konstruksi . Jakarta Selatan: PT. PLN (PERSERO).

59, S. N. (1985). Keandalan Pada Sistem Distribusi 20kV dan 6kV. Jakarta: Perusahaan Umum Listrik Negara.

Abdul, K. (2000). Distribusi dan Utilisasi Tenaga Listrik. Jakarta: Universitas Indonesia.
Sarimun, W. (2012). Proteksi Sistem Distribusi Tenaga Listrik. Bekasi: Garamond.

Suhadi, dkk. (2008). Teknik Distribusi Tenaga Listrik Jilid 1. Jakarta: Direktorat Pembinaan Sekolah Menengah Kejuruan

Suputra Widharma, dkk. (2014). Analisis Perancangan Sudut Pengaman Perisai (Shield) Pada Penyulang. Denpasar. Matrix 